\title{
Estudo do efeito do toe grinding na resposta em fadiga de juntas cruciformes feitas de aço ASTM A131 grau AH36
}

\author{
Study of the effect of toe grinding on fatigue \\ response of cruciform welded joints of \\ ASTM A131 grade AH36 steel
}

\author{
Gabriel Xavier Funes ${ }^{1}$, Kleber Eduardo Bianchi ${ }^{1}$, \\ Priscila Machado Amaro ${ }^{1}$
}

\begin{abstract}
${ }^{1}$ Escola de Engenharia - EE, FURG - Universidade Federal do Rio Grande, CEP: 96203-900, Rio Grande, RS e-mail: funes.gx@gmail.com, bianchi.kleber@gmail.com, mapriscila91@gmail.com
\end{abstract}

\section{RESUMO}

Os problemas devido à fadiga em componentes mecânicos e estruturais são recorrentes na indústria, sendo ainda mais preocupantes quando tais componentes apresentam uniões soldadas. Ao longo dos anos, estudos têm sido realizados com o objetivo de desenvolver procedimentos para aumentar a vida em fadiga desse tipo de união. Dentre tais procedimentos estão algumas técnicas aplicadas ao cordão ou filete após concluído o processo de soldagem. O presente trabalho científico tem por objetivo estudar o efeito, em termos de vida sob carga cíclica, da técnica conhecida globalmente por toe grinding, que consta da usinagem localizada do pé do cordão de solda. A ranhura resultante do processo propicia a redução do fator de concentração de tensões, bem como a retirada de microdefeitos. Mais especificamente, o estudo visou verificar a influência de tal processo na vida em fadiga de juntas cruciformes de Aço ASTM A131 Grau AH36, soldadas pelo processo Arame Tubular (Flux-Cored Arc Welding - FCAW) e submetidas a carregamento cíclico transversal. Para tal, procedimentos experimentais envolvendo diferentes áreas da fabricação foram utilizados para confeccionar os corpos de prova, dentre os quais, um processo pré-qualificado de soldagem, bem como técnicas de inspeção não destrutiva dos cordões. Mesmo assim, o corte lateral dos corpos de prova mostrou que as juntas apresentaram falta de penetração na raiz dos cordões. Em sequência, a amostra foi dividida em dois grupos - com e sem toe grinding - e os ensaios de fadiga foram realizados em condições semelhantes para ambos os grupos. Os resultados obtidos nos ensaios mostraram que o mecanismo de falha, no caso dos corpos de prova que não sofreram toe grinding, se tratou da propagação de microtrincas do tipo intrusão previamente localizadas no pé dos filetes de solda. Já os corpos de prova que passaram pelo toe grinding apresentaram migração do local de falha do pé para a raiz dos cordões de solda, bem como um aumento expressivo do valor médio de número de ciclos até a falha.

Palavras-chave: Junta cruciforme, Aço ASTM A131 Grau AH36, toe grinding, fadiga.

\section{ABSTRACT}

Failures of mechanical and structural components due to fatigue are unfortunately recurrent in industry and there is a special concern when these components contain welded joints. Over the years, studies have been carried out with the objective of developing procedures and techniques for fatigue life increasing of this type of joints. Among them, a set of techniques consisting of bead or fillet reworking after the welding process completion has been developed. Present work aims to evaluate the effect, in terms of life under cyclical load, of the toe grinding technique, which consists of a weld toe machining process employing a round tip tool. Such a process generates a shallow circular groove which allows the reduction of the stress concentration factor as well as microdefects removal. More specifically, the study focused on the influence of such process on the fatigue life of cruciform joints of ASTM A131 - Grade AH36 steel, welded by Flux Cored Arc Welding Process and subjected to transverse cyclic loading. Experimental procedures involving different manufacturing areas were applied for specimens preparation, including a prequalified welding process, as well as nondestructive weld bead inspection techniques. Even so, lateral cutting of the specimens evidenced lack of 
penetration at the root of the beads. After that, the sample was divided into two groups - with and without toe grinding application - and the fatigue tests were performed under similar conditions for both groups. The results obtained indicate that the failure mechanism, in the case of ordinary specimens, was the propagation of intrusion-type micro-cracks which were previously located at the weld toe. On the other hand, the specimens presenting toe grinding grooves suffered a failure site changing, from toe to the weld root, accompanied by an expressive increase in the number of cycles up to failure.

Keywords: Cruciform joint, ASTM A131 Grade AH36 steel, toe grinding, fatigue.

\section{INTRODUÇÃO}

Toda e qualquer estrutura de engenharia está sujeita a carregamentos estáticos, sejam eles ocasionados pelo peso próprio e de equipamentos fixados a essa estrutura, ou ainda por tensões adicionais secundárias, como por exemplo, as tensões residuais. Usualmente tais componentes mecânico-estruturais também estão sujeitos a carregamentos variáveis no tempo, os quais podem levar a uma ruptura repentina, por fadiga. Esse mecanismo de falha pode ocasionar a ruptura abrupta mesmo em materiais dúcteis, sem que haja deformação ou alongamento perceptível, em solicitações notoriamente inferiores à tensão de escoamento do material de base. De forma resumida, a falha por fadiga é caracterizada por apresentar três estágios distintos: de nucleação de uma ou mais trincas, de propagação das mesmas e, por fim, de falha final repentina. Tais trincas surgem em pontos onde haja nível elevado de tensões, propagando-se paulatinamente coma flutuação da carga $[1,2]$.

Durante o processo de fabricação de uniões soldadas, pequenas descontinuidades e imperfeições são inevitáveis e, dessa forma, pode-se considerar que o tempo de nucleação das trincas é simplesmente suprimido. Ou seja, esse período inicial de tempo, que em peças íntegras pode corresponder a $90 \%$ ou mais da vida útil, praticamente inexiste no caso de componentes soldados, o que se traduz numa redução importante da resistência à fadiga $[3,4,5,6]$.

Além disso, há outras questões que contribuem para a redução da vida em fadiga de uniões soldadas, quais sejam: $i$ ) o elevado fator de concentração de tensões associado à geometria dos cordões ou filetes e ii) as tensões residuais de grande magnitude. No caso de uma junta cruciforme unida por filetes, a concentração de tensões associada à descontinuidade geométrica é caracterizada pelo ângulo $\theta$ (weld toe angle) e pelo raio de tangência $r$ (weld toe radius), medidos no pé do filete, como mostrado na Figura 1. Os procedimentos que proporcionam a redução de $\theta$, ou o incremento de $r$, acarretam melhora do perfil geométrico do cordão de solda, resultando na redução da concentração de tensões $[7,8,9]$.

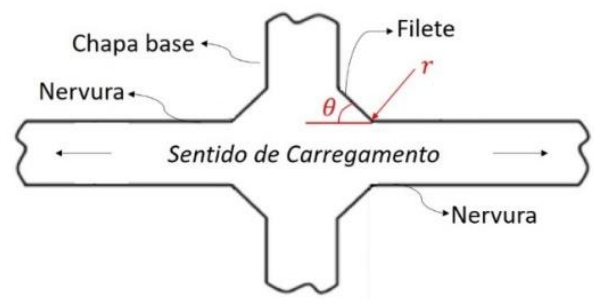

Figura 1: Parâmetros geométricos do pé da solda de filete em uma junta cruciforme.

Já a tensão residual é causada pela dilatação e contração térmica das sucessivas regiões fundidas pelo arco elétrico ao longo do processo de deposição de material. Como resultado, a região da solda apresenta, após o resfriamento, uma distribuição complexa de tensões residuais, ou seja, alguns locais apresentam tensões de tração e outros de compressão. Além disso, é usual que os valores máximos de tensão residual sejam da ordem da tensão de escoamento do material de menor resistência, quer seja o metal de base ou de adição [10].

Uma abordagem comum entre as normas voltadas ao projeto de estruturas compostas por uniões soldadas, sob o critério de fadiga, é o método da classificação, desenvolvido com base em três constatações experimentais: $i$ ) o valor médio de tensão atuante sobre o detalhe soldado não é preponderante para a vida em fadiga e, dessa forma, as análises são baseadas na amplitude de variação da tensão (com a ressalva de que o valor máximo dessa tensão não ultrapasse o limiar de escoamento generalizado da união), ii) no caso de aços estruturais convencionais, tanto a composição química como os dados de resistência mecânica não são determinantes para a resposta em fadiga (observação: entende-se por aço estrutural convencional, o que apresenta resistência ao escoamento $S_{\mathrm{y}}<690 \mathrm{MPa}$ ) e iii) diferentes arranjos geométricos de detalhes soldados e de carga atuante (transversal ou longitudinal aos cordões) podem apresentar comportamento semelhante. 
Com base nisso, têm sido obtidas, ao longo de décadas de ensaios, famílias de diagramas S-N para os principais detalhes soldados. Nesses casos, as estruturas de teste são fabricadas por meio de procedimentos já consolidados e pré-qualificados na indústria, bem como ensaiadas em condições semelhantes às encontradas em campo. Dessa forma, os comitês das entidades classificadoras reuniram tais dados em diagramas e tabelas, contendo a descrição geométrica e o tipo de carga atuante na união. Os detalhes soldados são classificados por meio de uma figura de mérito simples, por exemplo, o valor da amplitude de tensão associada a uma vida de $2 \times 10^{6}$ ciclos até a ruptura. Tal figura de mérito é denominada, dependendo da norma, como Classe de Fadiga (FAT - Fatigue Class) ou Categoria do Detalhe (Detail Category ou Joint Category). Por fim, a combinação entre a descrição geométrica e o tipo de carga atuante na união acarreta ainda na divisão em dois grandes grupos de classificação: uniões que suportam (load-carrying-joint) e que não suportam (non-loadcarrying-joint) carga $[4,5,11]$.

Dessa forma, tomando como exemplo a geometria da junta em estudo (união cruciforme com penetração completa e sem toe grinding), a qual é classificada na categoria 71, considera-se que tal união atingirá, quando sujeita a uma amplitude de tensão de $71 \mathrm{MPa}$, no mínimo 2 milhões de ciclos [4,5]. Tal método de classificação permite a comparação direta de diferentes uniões soldadas, sob o ponto de vista da resposta em fadiga. Por fim, uma Categoria do Detalhe elevada significa melhor resposta em fadiga e, portanto, essa informação é de grande valor na fase de definição da geometria da peça e da própria união.

Quanto ao toe grinding, tal técnica tem sido empregada em componentes críticos do setor naval e de estruturas offshore, os quais estão sujeitos a grande número de ciclos de carga, bem como ao próprio ambiente marinho, que potencializa a propagação de trincas. A técnica consiste na remoção de material no pé do cordão de solda, o que proporciona uma transição suave entre tal cordão e o metal de base, bem como o relaxamento de tensões residuais e a remoção das intrusões (trincas potenciais da ordem de centésimos de milímetro que são oriundas do próprio processo de soldagem) [11]. A remoção do material é realizada por meio de uma ferramenta de ponta esférica, acoplada a uma máquina rotativa manual e, portanto, é realizada por operador capacitado. A utilização dessa técnica não é adequada para juntas cuja combinação de configuração geométrica e de carregamento aplicado acarreta em uma falha na raiz e não no pé da solda [3, 9, 12, 13].

Com base no exposto, o objetivo do trabalho é o estudo do efeito do toe grinding na resposta em fadiga de juntas cruciformes de Aço ASTM A131 Grau AH36, soldadas pelo processo Arame Tubular e submetidas a carregamento transversal. A amostra é composta por dois grupos de corpos de prova: com e sem aplicação da técnica, o que torna possível uma análise comparativa entre os casos.

\section{MATERIAIS E MÉTODOS}

O processo de fabricação e de testes dos corpos de prova constou resumidamente das seguintes etapas: determinação das dimensões da junta, seleção do metal de adição, preparação das chapas e chanfros, soldagem, inspeção dos corpos de prova soldados, realização do toe grinding, inspeção dimensional e com líquido penetrante e, por fim, realização dos ensaios de fadiga.

\subsection{Geometria dos corpos de prova}

Tendo em vista que o toe grinding é bastante empregado em estruturas navais, adotou-se uma configuração geométrica de união típica dessas estruturas, qual seja, a junta cruciforme, cuja resposta em fadiga é relativamente pobre. Para definição das proporções globais dos corpos de prova, levou-se em consideração também a capacidade do equipamento de ensaio.

Adotou-se uma espessura de nervuras correspondente a $10 \mathrm{~mm}$. Já a espessura da chapa base transversal, de $20 \mathrm{~mm}$, foi escolhida para permitir uma configuração de união bastante rígida e possibilitar uma grande região para troca de calor durante o processo de soldagem. Por fim, adotou-se um valor de $35 \mathrm{~mm}$ para a largura dos corpos de prova e, por consequência, da própria junta. Os corpos de prova foram retirados da região central de uma junta maior, de forma a excluir as regiões inicial e final dos cordões, que naturalmente apresentam concentração de defeitos. Dessa forma, evitou-se uma possível causa de dispersão de resultados experimentais. As dimensões dos corpos de prova podem ser vistas na Figura 2. 


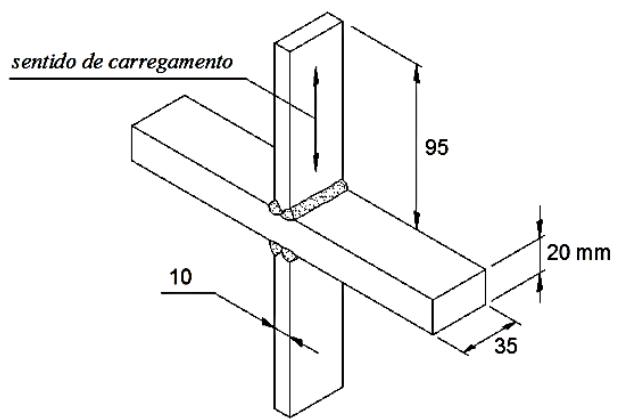

Figura 2: Dimensões principais dos corpos de prova.

Com base nos diagramas S-N da norma Eurocode 3 - seção 1.9 [4] para a categoria 71, uma faixa de tensões normais de $170 \mathrm{MPa}$ proporciona uma vida estimada de $145 \mathrm{mil}$ ciclos. No caso de uma razão de carga de ensaio $\mathrm{R}=0\left(\mathrm{R}=\mathrm{F}_{\text {mínima }} / \mathrm{F}_{\text {máxima }}=\sigma_{\text {mínima }} / \sigma_{\text {máxima }}\right)$, o valor de $170 \mathrm{MPa}$ corresponde ao pico de tensão normal. Nessa condição, para a geometria de corpos de prova adotada e para tal valor de pico de tensão, a carga máxima de ensaio corresponde a aproximadamente $60 \%$ da capacidade do equipamento.

Cabe colocar ainda que, na preparação para a soldagem, as pontas das nervuras foram chanfradas, com o intuito de proporcionar cordões com penetração total. A raiz do primeiro cordão foi goivada, para então ser realizado o segundo. A forma final dos cordões apresentou uma face com reforço.

\subsection{Características mecânicas do metal de base}

O aço estrutural microligado ASTM A 131 Grau AH36 apresenta um valor mínimo de resistência ao escoamento de $355 \mathrm{MPa}(51 \mathrm{ksi})$ e uma faixa de resistência à tração admissível de 490 a $620 \mathrm{MPa}(71-90 \mathrm{ksi})$. Tais propriedades mecânicas são obtidas por meio da adição de baixos teores de alumínio, vanádio ou nióbio, que proporcionam uma granulometria fina [14].

\subsection{Fabricação dos corpos de prova}

O material utilizado, bem como a mão-de-obra para a fabricação dos corpos de prova, foram concedidos pela empresa RVT Construtora Sul. Como mencionado, os corpos de prova foram retirados de uma junta maior, cujas placas foram cortadas por processo oxicorte nas seguintes dimensões: a) Placas de $10 \mathrm{~mm}$ de espessura: $95 \mathrm{~mm}$ x $70 \mathrm{~mm}$ e $b$ ) Placa de $20 \mathrm{~mm}$ de espessura: $100 \mathrm{~mm}$ x $200 \mathrm{~mm}$. As dimensões maiores dessas placas estavam alinhadas com o sentido de laminação das chapas.

Com o intuito de garantir o nível de confiabilidade necessário, o processo de soldagem foi baseado em parâmetros especificados na norma AWS D1.1(2010) para procedimentos pré-qualificados. Tais parâmetros são mostrados na Tabela 1. Como tal norma estabelece o uso de um metal de adição com resistência igual ou maior àquela do metal de base, adotou-se o arame-eletrodo AWS Classe A5.20 - E71T-1CJ, juntamente com o gás de proteção $\mathrm{CO}_{2}(100 \%)$. Além disso, vale destacar que foram realizados três passes por cordão: de raiz, de preenchimento e de acabamento.

Tabela 1: Parâmetros de Soldagem

\begin{tabular}{l|c|c|l|l|l}
\hline \multicolumn{1}{c|}{ PASSE } & $\begin{array}{c}\text { FAIXA DE } \\
\text { TENSÃO }\end{array}$ & $\begin{array}{c}\text { FAIXA DE } \\
\text { CORRENTE }\end{array}$ & POLARIDADE & $\begin{array}{c}\text { DIÂMETRO } \\
\text { DO } \\
\text { ELETRODO }\end{array}$ & $\begin{array}{c}\text { VAZÃO DO } \\
\text { GÁS DE } \\
\text { PROTEÇÃO }\end{array}$ \\
\hline Passe de raiz & $24-28(\mathrm{~V})$ & $180-210(\mathrm{~A})$ & \multirow{2}{*}{$\mathrm{C}+$} & $1,2(\mathrm{~mm})$ & $19(1 / \mathrm{min})$ \\
\cline { 1 - 4 } Passe de preenchimento & $28-30(\mathrm{~V})$ & $190-220(\mathrm{~A})$ & & \\
\hline Passe de acabamento & & & & \\
\hline
\end{tabular}

Antes da soldagem propriamente dita houve processo de preparação dos chanfros e pré-fixação das chapas por meio de pontos de solda. No processo de soldagem da nervura à placa intermediária, concluído o passe de raiz do primeiro lado, realizou-se então sua goivagem, seguida pela execução do passe de raiz no 
lado oposto. Os demais passes intermediários e de acabamento também foram realizados de forma alternada.

Ao final da soldagem, observou-se a presença de respingos e de mordeduras na região do canto da chapa de menor espessura. Após o resfriamento completo, os respingos foram removidos.

Finalizada a etapa de soldagem, foi então realizado ensaio não destrutivo por ultrassom, para verificação da integridade dos cordões de solda. O procedimento é melhor explicado em seção posterior.

Por fim, os corpos de prova foram cortados nas dimensões finais por meio de serra-fita. Um total de 6 corpos de prova foi fabricado.

\subsection{Realização do processo de toe grinding}

O processo de usinagem do pé do cordão deve ser efetuado de modo que as ranhuras de corte resultantes sejam, tanto quanto possível, paralelas ao sentido de aplicação da carga. Para tal, é necessário um posicionamento angular adequado da ferramenta durante o processo. As Figura 3(a) e 3(b) apresentam os ângulos de ataque da ferramenta utilizados. Já a figura 3(c) apresenta dois casos de geometria da ranhura resultante. Caso o posicionamento e profundidade da ranhura sejam inadequados, o processo não será efetivo.
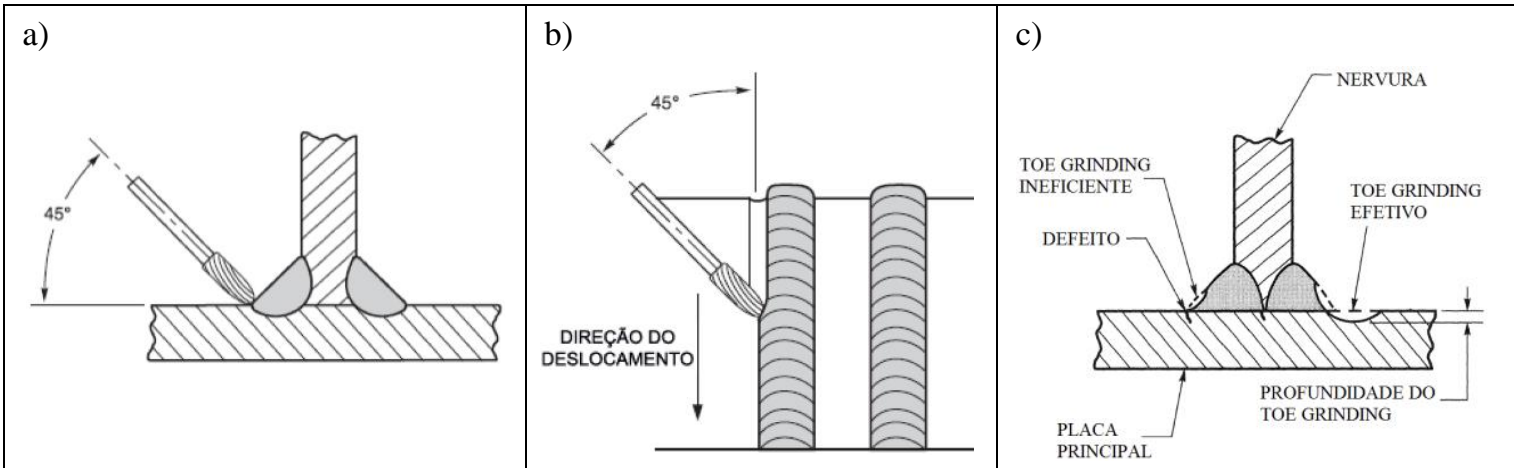

Figura 3: Execução do toe grinding: a) e b) ângulos de ataque da ferramenta; c) eficácia da geometria esperada.

Na Figura 4 é mostrada, por simplicidade, uma união em T, cujas propriedades mecânico-estruturais são idênticas às da junta cruciforme. Observa-se que há duas regiões ("Toe 1" e "Toe 2") candidatas ao processo de toe grinding. Porém, conforme as recomendações, tal processo deve ser realizado na chapa sobre a qual atua a carga; nesse caso, a "Toe 2" [9]. Seguindo as mesmas recomendações, o raio de ranhura adotado foi de $5 \mathrm{~mm}$ e a profundidade alcançada no pé do cordão ficou entre 0,5 e $1,0 \mathrm{~mm}$. A adoção de um valor relativamente baixo de profundidade teve por objetivo evitar a redução excessiva da seção transversal da placa de $10 \mathrm{~mm}$ de espessura. Caso contrário, o toe grinding, ao invés de melhorar a vida em fadiga, poderia trazer resultados deletérios $[5,12,13]$.

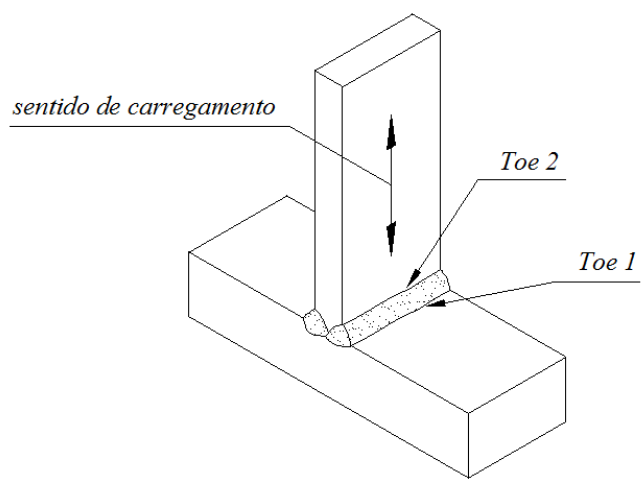

Figura 4: União em T ilustrando a região retificada (toe 2) do cordão.

Por fim, foi realizado ensaio com líquido penetrante para verificação da existência de defeitos superficiais na ranhura, bem como a averiguação das dimensões finais obtidas no processo. Tais procedimentos são 
melhor explicados na próxima seção.

\subsection{Inspeções}

\subsubsection{Inspeção por ultrassom}

A realização da inspeção por ultrassom foi realizada por meio do contato direto de cabeçotes angulares (miniatura) de ondas transversais sobre a superfície da peça. Anteriormente, quaisquer pequenas irregularidades da superfície e respingos de solda foram retirados, tendo sido então a superfície devidamente limpa de óxidos e sujidades. Além disso, para conseguir executar a varredura, fez-se uso do elemento acoplante carboximetil-celulose. Os movimentos foram executados de forma que a área coberta pela varredura do cabeçote, na chapa de $10 \mathrm{~mm}$, fosse suficiente para examinar o metal de solda e a zona afetada pelo calor em todos os cordões. Naquele momento, julgou-se que tal procedimento seria adequado para a detecção de descontinuidades longitudinais e transversais ao cordão de solda. Na Figura 5 é possível observar o momento em que as peças foram ensaiadas, junto ao equipamento.

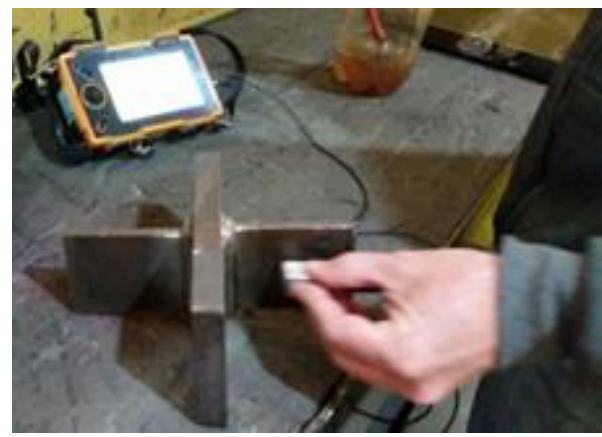

Figura 5: Ensaio com ultrassom.

\subsubsection{Inspeção por líquido penetrante}

O ensaio com líquido penetrante foi realizado sobre as peças já finalizadas, na região submetida ao toe grinding, para verificação de possíveis descontinuidades inerentes ao próprio processo ou decorrentes do processo de soldagem. Algumas etapas do ensaio são mostradas na Figura 6.

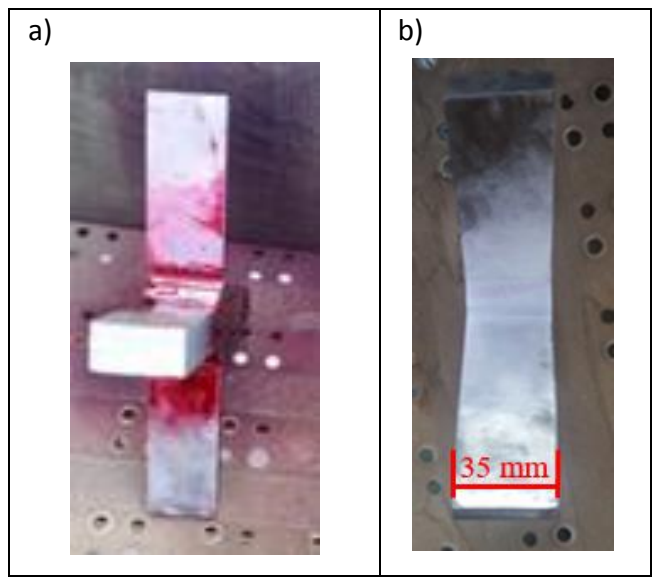

Figura 6: Parte dos corpos de prova com: a) líquido penetrante aplicado e; b) revelador aplicado

\subsubsection{Inspeção dimensional da geometria da ranhura resultante do toe grinding}

A fim de garantir que a geometria da ranhura de toe grinding estivesse de acordo com as recomendações mostradas no item 2.4, o raio foi verificado por meio do uso de gabarito, enquanto que a profundidade foi verificada por meio de um calibrador de solda. Tais procedimentos são mostrados na Figura 7. 


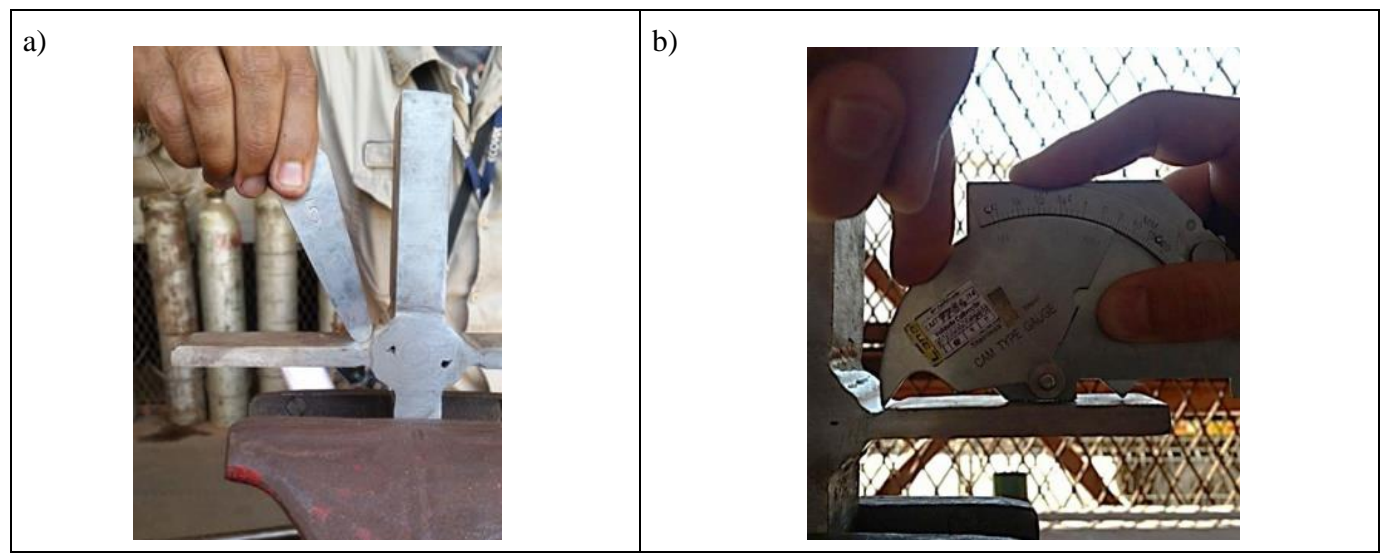

Figura 7: a) Verificação do raio obtido, utilizando gabarito e; b) Verificação da profundidade obtida no pé do cordão de solda realizada por meio do calibrador de solda.

\subsection{Ensaios de fadiga}

Para o ensaio sob carga de fadiga, adotou-se carregamento idêntico para corpos de prova cuja única diferença se tratava da presença ou não da ranhura de toe grinding. Aplicou-se uma carga de forma senoidal, com razão de carga $\mathrm{R}=0$ e frequência de $10 \mathrm{~Hz}$, numa máquina servo-hidráulica Shimadzu modelo EHF-EV200K1020-1A, cuja capacidade de carga é de 100 kN para carga dinâmica. Pelas características geométricas das peças e da união soldada, o sentido de carregamento foi transversal aos cordões e paralelo ao sentido de laminação das chapas. Os ensaios ocorreram em condições normais de temperatura e umidade relativa do ar, aproximadamente $20^{\circ} \mathrm{C}$ e $80 \%$, respectivamente. Além disso, foram realizadas medições da largura dos corpos de prova, para obtenção do real comprimento dos cordões após o corte. Dessa forma, o valor da carga de ensaio foi corrigida de forma a garantir que a tensão sobre os cordões fosse a mesma para todos os corpos de prova.

\section{RESULTADOS E DISCUSSÕES}

Anteriormente à apresentação dos resultados associados ao processo de toe grinding é importante ressaltar um fato inesperado que ocorreu no processo de preparação dos corpos de prova, fato esse relacionado à integridade dos cordões de solda.

A inspeção por ultrassom havia indicado que os cordões de solda não apresentavam defeitos importantes, ou seja, de acordo com os critérios associados a esse processo de inspeção, tais cordões poderiam ser considerados íntegros. Porém, após o corte dos corpos de prova para obtenção das dimensões finais, constatou-se a presença de defeitos importantes na raiz dos cordões de todas as peças, caracterizados pela falta de penetração e acúmulo de escória. A figura 8 mostra imagens da região defeituosa e da análise macrográfica efetuada sobre um dos corpos de prova.

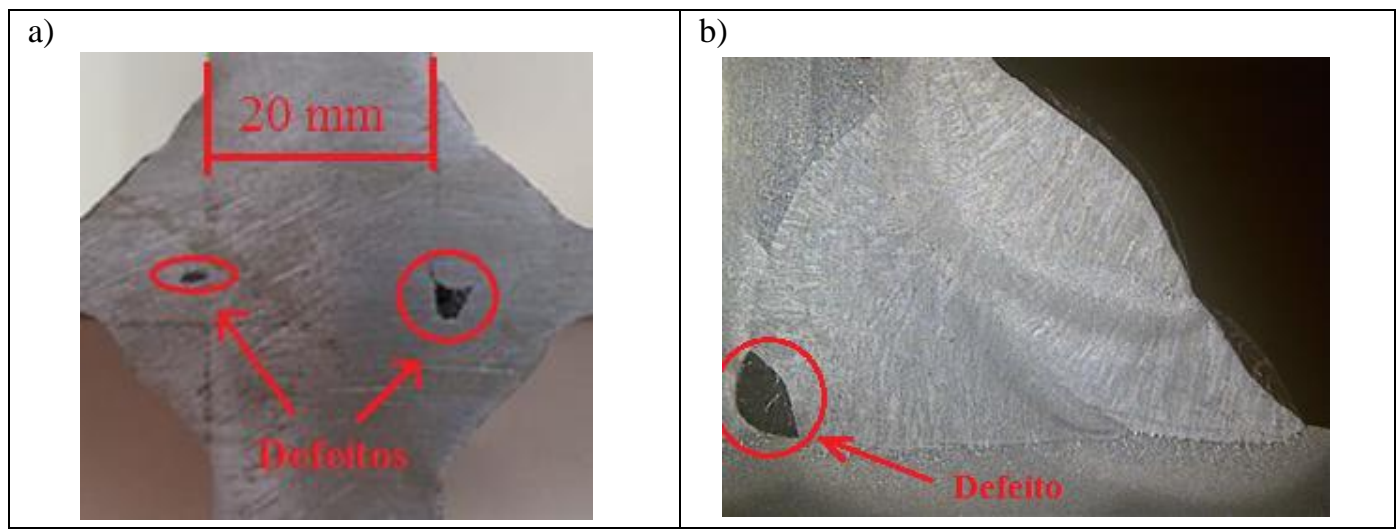

Figura 8: a) defeitos nos corpos de prova; b) Macrografia mostrando região do defeito (Nital 2\% - 6,5x)

A constatação desses defeitos foi causa de grande preocupação, pois todo o trabalho de preparação dos corpos de prova poderia ter sido em vão, tendo em vista que o processo de propagação de trincas de fadiga 
poderia ocorrer na raiz, e não no pé da solda. Nesse caso, o processo de toe grinding não teria efeito nenhum nos resultados. Por outro lado, observou-se que todos os corpos de prova apresentavam defeitos de proporções semelhantes e, além disso, como mostra claramente a figura 8, os cordões apresentavam uma grande região de reforço, o que propiciava um fluxo de forças relativamente suave. Diante desses fatos, optou-se pela execução dos ensaios de fadiga sobre os corpos de prova defeituosos, de forma exploratória.

Os demais procedimentos de inspeção, cujo objetivo era a avaliação da adequação das ranhuras originadas no processo de toe grinding, não indicaram problemas dimensionais ou anormalidades.

Quantos aos ensaios de fadiga, a Tabela 2 mostra as faixas de cargas aplicadas, corrigidas de acordo com a largura dos corpos de prova, bem como os resultados obtidos, em termos de números de ciclos até a falha. O valor aproximado da carga foi estabelecido com base na Categoria do Detalhe 71 da norma Eurocode 3 - Seção 1.9 [4], correspondente a uma união em T ou cruciforme. Para tal, adotou-se uma meta de vida de aproximadamente 145 mil ciclos.

Os resultados obtidos, mais do que mostrar a adequação da união ensaiada quanto à sua Categoria do Detalhe (tendo em vista que os dados da norma adotada são claramente conservativos), evidenciam o ganho expressivo de vida obtido com o emprego do toe grinding. No caso do corpo de prova CP2T, observou-se que a trinca de fadiga teve início na região defeituosa da raiz. Portanto, o resultado de vida desse corpo de prova não pode ser diretamente comparado aos obtidos nos corpos de prova sem toe grinding. Contudo, é importante observar que todos os corpos de prova sem toe grinding apresentaram falha por fadiga no pé do cordão. Em outras palavras, a aplicação de tal processo ao corpo de prova CP2T ocasionou a mudança do sítio de falha, ou seja, o pé do cordão deixou de ser o ponto crítico da união.

Tabela 2: Resultados obtidos nos ensaios de fadiga.

\begin{tabular}{|c|c|c|c|c|c|}
\hline & Corpo Prova & Largura & Faixa de Cargas & № ciclos & Observações \\
\hline \multirow{3}{*}{$\begin{array}{c}\text { SEM TOE } \\
\text { GRINDING }\end{array}$} & $\mathrm{CP} 1$ & $38,5(\mathrm{~mm})$ & $0-65,45(\mathrm{kN})$ & 480.592 & Ruptura no pé da solda \\
\hline & $\mathrm{CP} 2$ & $35,1(\mathrm{~mm})$ & $0-59,67(\mathrm{kN})$ & 947.726 & Ruptura no pé da solda \\
\hline & $\mathrm{CP} 3$ & $35,5(\mathrm{~mm})$ & $0-60,35(\mathrm{kN})$ & 1.391 .583 & Ruptura no pé da solda \\
\hline \multirow{2}{*}{$\begin{array}{l}\text { COM TOE } \\
\text { GRINDING }\end{array}$} & $\mathrm{CP} 2 \mathrm{~T}$ & $32,1(\mathrm{~mm})$ & $0-58,75(\mathrm{kN})$ & 3.865 .660 & Ruptura com início no defeito \\
\hline & CP3T & $34,8(\mathrm{~mm})$ & $0-54,19(\mathrm{kN})$ & 10.967 .338 & Ruptura no pé da solda \\
\hline
\end{tabular}

Já o corpo de prova CP3T apresentou vida bastante elevada, superior a 10 milhões de ciclos. Não obstante a grande discussão no meio científico quanto à validade do emprego de um valor limite de fadiga em peças de engenharia, principalmente no caso de uniões soldadas, observa-se que as curvas S-N da norma Eurocode 3 - seção 1.9 - apresentam uma primeira inflexão em 5 milhões de ciclos (onde passam a apresentar inclinação menor) e uma nova inflexão em 100 milhões de ciclos, ponto estabelecido como limiar de vida infinita. Portanto, mesmo que não tenha havido ruptura final do corpo de prova CP3T, observou-se que o processo de toe grinding propiciou uma resposta situada não mais na região de vida finita, dentro da qual são usualmente dimensionadas as uniões estruturais, mas numa região de vida extrema (mesmo que não possa ser considerada infinita). Por fim, o corpo de prova com toe ginding CP1T teve seu ensaio interrompido e o resultado deste não pode ser considerado.

A Figura 9 mostra o aspecto das fraturas ocorridas nos corpos de prova CP1 e CP2T, com imagem adicional das respectivas seções finais de ruptura. Sobre essas faces de ruptura foram delineadas as regiões 1, 2 e 3, as quais correspondem, sequencialmente, aos locais de nucleação, de propagação e de ruptura final. 


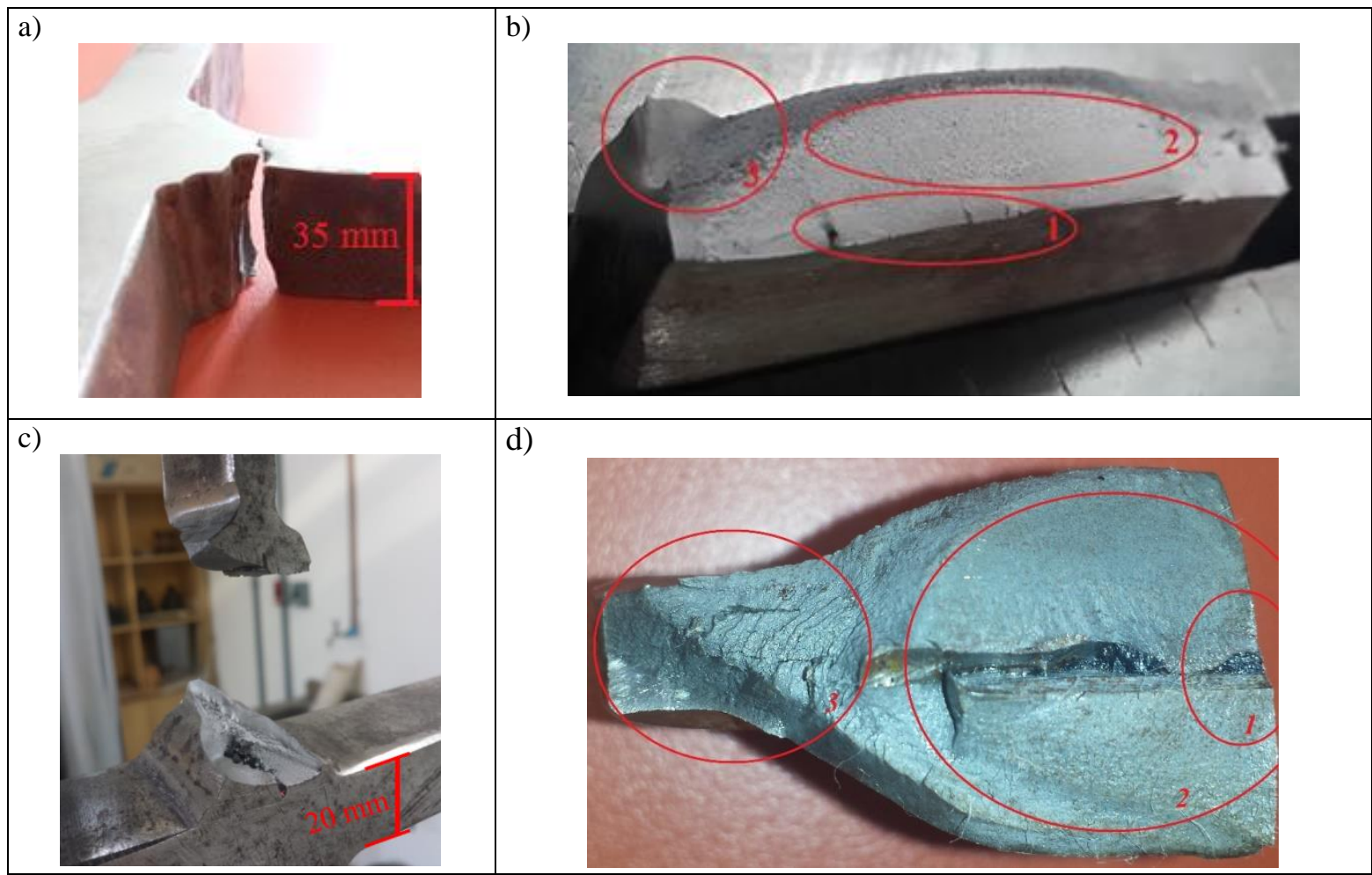

Figura 9: a) ruptura de um $\mathrm{CP}$ sem toe grinding, b) seção de ruptura do $\mathrm{CP}$ sem toe grinding, c) ruptura de um $\mathrm{CP}$ com toe grinding, b) seção de ruptura do CP com toe grinding (obs.: a peça foi seccionada na região de nucleação).

Por meio da Figura 9(b) é possível observar que a região 1 do corpo de prova CP1 (que não sofreu processo de toe grinding) apresenta mais do que uma trinca originária. A grande diferença de desempenho ocorrida entre os corpos de prova com e sem o toe grinding indica que, no caso de uniões cruciformes, o processo de soldagem FCAW gera falhas do tipo intrusão no pé dos cordões. Dessa forma, pode-se apreender que, no caso de peças que não passaram pelo toe grinding, o período de nucleação de trincas praticamente inexiste. Portanto, é coerente admitir que pelo menos uma microtrinca tipo intrusão passa a se propagar já nos primeiros ciclos de carga. Da mesma forma é razoável considerar que a correta aplicação do toe grinding às uniões cruciformes propicia um período de nucleação que, do contrário, não existiria.

\section{CONCLUSÕES}

Os ensaios de fadiga realizados em corpos de prova cruciformes, cuja união foi efetuada por processo de soldagem FCAW, comprovaram que o mecanismo de falha ocorre por meio da propagação de microtrincas tipo intrusão localizadas no pé dos cordões. A disposição dessas trincas, transversais ao fluxo de forças, confere uma condição favorável à propagação.

Por outro lado, os corpos de prova que sofreram o processo de usinagem dos pés dos cordões apresentaram ganhos de vida excepcionais, da ordem de 5 vezes. Portanto, no caso específico desse tipo de união e de processo de soldagem, a aplicação do processo de toe grinding é completamente justificada.

Uma questão relacionada ao processo de inspeção por ultrassom, apesar de inesperada, mostrou-se relevante nesse estudo. Observou-se que as falhas na raiz da solda são de difícil detecção no caso de uniões cruciformes. Portanto, no caso de componentes críticos com tal geometria de união, a aplicação do toe grinding no pé dos cordões ou filetes pode não ser suficiente para garantir a vida desejada. Nesse caso, também é necessário o emprego de processos de soldagem e de inspeção que garantam a integridade da região da raiz de tais cordões. Caso isso não ocorra, a aplicação do toe grinding, ao invés de garantir vida elevada, ocasionaria apenas a alteração do locus originiário da falha, do pé para a raiz do cordão de solda.

O procedimento de ensaio adotado se mostrou adequado, porém, deve ser estendido a outras geometrias de união em que o toe grinding possa ser aplicado, bem como a outros processos de soldagem. A elaboração de um conjunto de dados consistente sobre a influência do toe grinding pode propiciar, no futuro, a inserção de parâmetros de correção de desempenho em fadiga, nas normas que regem a construção de estruturas de engenharia soldadas. 


\section{AGRADECIMENTOS}

Os autores agradecem a empresa RVT pelo fornecimento de mão de obra e material para fabricação dos corpos de prova e também aos Laboratório de Ensaios Mecânicos e de Metalografia da Universidade Federal do Rio Grande - FURG, que concederam os equipamentos necessários para realização dos ensaios de fadiga e análises metalográficas.

\section{BIBLIOGRAFIA}

[1] NORTON, R. L., Projeto de máquinas: Uma abordagem integrada, 4 ed, Porto Alegre, Bookman, 2013.

[2] NISBETT, J. K., BUDYNAS, R. G., KEITH, N. J., Elementos de máquinas de Shigley: Projeto de engenharia Mecânica, 8 ed, Porto Alegre, AMGH, 2011.

[3] BRANCO, C. M., FERNANDES, A. A., CASTRO, P. M. S. T. Fadiga de Estruturas Soldadas, 2 ed, Lisboa, Fundação Calouste Gulbenkian, 1999.

[4] EUROPEAN STANDARD, Eurocode 3: Design of steel structures - Part 1.9: Fatigue, 2003.

[5] HOBBACHER, A., Recommendations for Fatigue Design of Welded Joints and Components, In: Doc. XIII-2151r4-07/XV-1254r4-07, International Institute of Welding, 2008.

[6] LASSEN T., RÉCHO N., Fatigue Life Analyses of Welded Structures: Flaws, 1 ed, Londres, ISTE, 2006.

[7] NGOULA, D. T., BIER, H.TH. VORMWALD, M. "Fatigue crack growth in cruciform welded joints: Influence of residual stresses and of the weld toe geometry", International Journal of Fatigue, Available online September, 2016.

[8] CACCESE, V., BLOMQUIST, P. A., BERUBE, K. A., et al, "Effect of weld geometric profile on fatigue life of cruciform welds made by laser/GMAW processes", Marine Structures, v. 19, n. 1, pp. 1-22, Jan. 2006 [9] AMERICAN BUREAU OF SHIPPING, Guide for Shipbuilding and Repair Quality Standard For Hull Structures During Construction, Houston, 2007.

[10] HICKS, J., Welded joint design, 3 ed, New York, Industrial Press, 1999.

[11] AMERICAN WELDING SOCIETY, Structural Welding Code - Steel. D1.1/D1.1M, 2010.

[12] KIRKHOPE, K. J., BELL, R., CARON, L., et al, "Weld detail fatigue life improvement techniques. Part 1: review". Marine structures, v. 12, n. 6, pp. 447-474, July, 1999.

[13] HAAGENSEN, P. J., MADDOX, S. J., IIW Recommendations on Post Weld Improvement of Steel and Aluminium Structures, In: Doc. XIII-1815-00, International Institute of Welding, 2006.

[14] AMERICAN BUREAU OF SHIPPING, Rules for Materials and Welding - Part 2., Houston, 2010. 